\title{
AVALIAÇÃO DE UMA MICROIMUNODIFUSÃO EM GEL DE ÁGAR PARA DIAGNÓSTICO DE LENTIVÍRUS DE PEQUENOS RUMINANTES (LVPR) EM CAPRINOS
}

\author{
Emmanuela Tiné de ArrudA ${ }^{1}$, Michele Moreira Martins OliveirA ${ }^{2}$, SÉrgio Alves do \\ NASCIMENTO $^{3}$, AnA Claudia CAMPOS $^{4}$, RoBerto SOARES DE CASTRO ${ }^{5}$

\footnotetext{
${ }^{1}$ Mestre em Ciência Animal - Universidade Federal Rural de Pernambuco - Recife, PE
${ }^{2}$ Professora Doutora da Faculdade de Imperatriz (FACIMP), Imperatriz, MA - michelemoreira2005@gmail.com

${ }^{3}$ Biológo da Universidade Federal Rural de Pernambuco, Recife, PE

${ }^{4}$ Doutoranda do Programa de Pós-graduação em Ciência Veterinária da Universidade Federal Rural de Pernambuco (UFRPE), Recife, PE

${ }^{5}$ Professor Associado da Universidade Federal Rural de Pernambuco (UFRPE), Recife, PE
}

As lentiviroses de Pequenos Ruminantes - LVPR (Artrite - encefalite Caprina - CAE e Maedi-Visna) acometem caprinos e ovinos e são caracterizadas por curso lento e progressivo, no qual a maioria dos animais acometidos não apresenta sintomatologia clínica. Assim, a sorologia é a forma mais prática de diagnóstico, pois a presença de anticorpos demonstra indiretamente a existência da infecção por LVPR. Este trabalho foi desenvolvido com o objetivo de avaliar uma microimunodifusão em gel de ágar (micro-IDGA), que utiliza $10 \mu \mathrm{L}$ de antígeno e soro controle positivo e $30 \mu \mathrm{L}$ do soro teste, comparativamente com uma macro-IDGA, que utiliza $20 \mu \mathrm{L}$ de todos os reagentes, para o diagnóstico sorológico de LVPR em caprinos.
Os testes foram comparados com base no índice de concordância ajustada (Kappa - K). Os cálculos foram feitos de acordo com os resultados do teste de 447 amostras de soro caprino colhidos de criações dos estados de Pernambuco, Paraíba e Rio Grande do Norte. Foram registrados $63(14,09 \%)$ resultados positivos na micro-IDGA e $60(13,42 \%)$ na macroIDGA, correspondendo à significativa concordância entre os testes $(k=0.90)$. Além disso, a micro-IDGA apresentou linhas mais claras do que as observadas na macro-IDGA, com resultados que podem ser lidos 24 horas mais cedo do que a macro-IDGA. Conclui-se que a micro-IDGA pode substituir a macro-IDGA no diagnóstico sorológico das LVPR.

PALAVRAS-CHAVE: CAEV; caprinos; diagnóstico; IDGA; Maedi-Visna.

\section{EVALUATION OF AGAR GEL MICROIMUNODIFUSION FOR DIAGNOSIS OF SMALL RUMINANT LENTIVIRUSES (SRLV) IN GOATS}

\section{ABSTRACT}

Small Ruminant Lentiviruses - SRLV (Caprine Arthritis - encephalitis - CAE and Maedi-Visna) infections are characterized by slow and progressive course, in which the majority of the animals do not present symptoms. Thus, the serological tests are the most practical diagnostic tool as the presence of antibodies indirectly indicates SRLV infection. This work was carried out with the objective of evaluating an agar gel micro-immunodifusion (micro-AGID) test in comparison with a macro-AGID test to be used in the serological diagnostic of SRLV in goats. In the micro-
AGID, $10 \mu \mathrm{L}$ of antigen and control serum and $30 \mu \mathrm{L}$ of test serum were used; in the macro-AGID, $20 \mu \mathrm{L}$ of sera and antigen were used. The tests were compared through the adjusted agreement index (Kappa - k) calculated according to 447 samples of goat serum from Pernambuco, Paraíba and Rio Grande do Norte states. Of 447 samples, $63(14.09 \%)$ and $60(13.42 \%)$ were positive to micro-AGID and macro-AGID, respectively, corresponding to a significant agreement between the tests $(k=0.90)$. Furthermore, the micro-AGID presented clearer lines than the macro-AGID and the 
results may be recorded 24 earlier in micro-AGID. Thus, the micro-AGID may replace the macro-AGID in the serological SRL diagnosis.

KEYWORDS: AGID; CAEV; diagnostic; Goat; Maedi-Visna.

\section{INTRODUÇÃO}

Os caprinos e ovinos podem ser infectados por um grupo de vírus genericamente denominado de Lentivírus de Pequenos Ruminantes (LVPR), que compreendem vários isolados, distribuídos em quatro grupos filogenéticos que compartilham similaridade genética, mecanismo molecular de replicação, morfologia e interação biológica com os hospedeiros. Os protótipos dos dois grupos principais são os vírus Maedi - Visna (MVV), também denominado Pneumonia Progressiva Ovina (OPPV), e o vírus da Artrite-Encefalite Caprina (CAEV), originalmente isolados de ovinos $\mathrm{e}$ caprinos, respectivamente (SHAH, 2004).

A enfermidade caracteriza-se por longo período de incubação, evolução lenta e progressiva, ficando os animais infectados portadores permanentes do vírus. Esses animais podem apresentar cinco quadros clínicos principais: artrite, encefalite, mamite, pneumonia e emagrecimento crônico (CALLADO et al., 2001). A transmissão dos LVPR ocorre principalmente pela ingestão de colostro e leite de fêmeas infectadas e por via respiratória, mais frequente em períodos de confinamento. Estudos sugerem que a transmissão vertical desse vírus pode ocorrer em condições naturais; entretanto, o mecanismo e a frequência não são conhecidos. O sêmen para inseminação artificial e a transferência de embrião representam o menor risco e o risco mínimo, respectivamente (CRUZ, 2009). Os animais infectados soroconvertem em diferentes períodos, às vezes tardiamente; há registros de certos casos de sororeversão (RIMSTAD et al., 1993; de ANDRÉS et al., 2005).

A suspeita da infecção por LVPR pode ser feita clinicamente, embora somente uma proporção pequena dos animais desenvolva sinais clínicos, ou de forma mais precisa, através da sorologia. Várias técnicas estão disponíveis para essa finalidade, como: imunodifusão em gel de ágar (IDGA), ensaios imunoenzimáticos (ELISA), radioimunoprecipitação (RIPA), radioimunoensaio (RIA) e western blotting (WB) (de ANDRÉS et al., 2005). A IDGA é o teste sorológico mais usado, pois apresenta boa aceitação pelo baixo custo, boa especificidade e praticidade de execução; contudo, tem sensibilidade inferior quando comparada ao ELISA e sua interpretação é relativamente subjetiva, requerendo experiência do executor. Por outro lado, o ELISA é um teste de custos mais elevados do que a IDGA. Ambos os testes são atualmente recomendados pela OIE para certificação (OIE, 2010). Em relação à IDGA, vários protocolos já foram desenvolvidos, usando-se diferentes antígenos, formulações de géis, formato, tamanho e distância entre os poços do molde para perfuração do gel, bem como seu arranjo no molde. Com base na quantidade dos reagentes utilizados, todos se referem à macro-IDGA (de ANDRÉS et al., 2005).

O Ministério da Agricultura, Pecuária e Abastecimento (MAPA) criou o Programa de Sanidade Caprina e Ovina (PNSCO) (BRASIL, 2004a) que contempla um Plano Nacional de Vigilância e Controle de Lentiviroses de Pequenos Ruminantes (PNVCLVPR) (BRASIL 2004b) no qual são apresentadas propostas que visam a diminuir o impacto dos principais fatores de risco para disseminação das lentiviroses nos rebanhos caprino e ovino. Esse plano engloba a adoção de medidas de biossegurança, tais como as medidas de manejo descritas anteriormente, e o diagnóstico das lentiviroses como ferramentas para o controle das LVPR. O diagnóstico de rotina preconizado é a imunodifusão em gel de agar (IDGA), devendo ser realizado o western blotting (WB) em casos duvidosos ou para certificação.

No Brasil, foram desenvolvidos alguns protocolos de macro-IDGA usando-se $30 \mu \mathrm{L}$ ou $100 \mu \mathrm{L}$ (GOUVEIA, 1994), ou $100 \mu \mathrm{L}$ de antígeno CAEV (ABREU et al., 1998). Este foi aperfeiçoado para $20 \mu \mathrm{L}$ e encontra-se comercialmente disponível (Biovetech - Recife, PE, Brasil.). O presente trabalho foi desenvolvido com o objetivo de avaliar uma micro-IDGA comparativamente a uma macro-IDGA para ser utilizada no diagnóstico sorológico de LVPR em caprinos (Para efeito deste artigo foi definido como macro-IDGA o teste realizado com $20 \mu \mathrm{L}$ ou mais do antígeno e do soro controle positivo e como micro-IDGA aquele realizado com menos de $20 \mu \mathrm{L}$.).

\section{MATERIAL E MÉTODOS}

Foi utilizada a amostra viral padrão CAEV Cork (CAEV-Co), multiplicada em células de cultivo primário, obtidas por explantação de membrana 
sinovial de feto caprino (MSC). As monocamadas celulares forma estabelecidas em garrafas plásticas com $125 \mathrm{~cm}^{2}$ de área de cultivo e inoculadas com 3,0 mL de uma suspensão viral de CAEV-Co com título de $10^{-4,3}$, adicionando-se $100 \mathrm{~mL}$ de Meio Essencial Mínimo de Eagle (MEM), suplementado com $2 \%$ de soro caprino (SC) comercial, e incubadas em estufa a $37^{\circ} \mathrm{C}$. No $5^{\circ}$ e $10^{\circ}$ dia pós-inoculação (PI), procedeu-se à avaliação da camada celular quanto à formação de efeito citopático (ECP). A partir do $10^{\circ}$ dia PI, a cada três dias, colheu-se o sobrenadante de cada garrafa, acrescentando-se $200 \mathrm{~mL}$ de MEM com 2\% de SC. Esse sobrenadante era estocado a $-20^{\circ} \mathrm{C}$, até o momento dos passos de purificação.

Após descongelamento dos sobrenadantes, procedeu-se à centrifugação a $3.300 \mathrm{~g}$ por 30 minutos e diálise em membrana (THOMAS SCIENTIFIC Swedesboro, NJ, USA $(3787-d 10)-(33 \times 21 \mathrm{~mm}))$ contra Polietilenoglicol (PEG 8.000) a 10\% em PBS $(\mathrm{pH} 7,6)$ a $4^{\circ} \mathrm{C}$, durante 48 a 72 horas, até a concentração de aproximadamente 50 - 100 vezes, quando foi coletado e estocado a $-20^{\circ} \mathrm{C}$ (ABREU et al., 1998). O antígeno foi diluído em PBS (pH 7,6) e titulado, em diluições duplas, frente ao soro padrão e usado como duas unidades precipitantes (UP).

O soro padrão foi preparado a partir do plasma de um animal naturalmente infectado com LVPR, com resultado positivo na macro-IDGA. O plasma foi centrifugado a $3.300 \mathrm{~g}$ por 30 minutos, a $4^{\circ} \mathrm{C}$ e diluído, 1:2 (v/v), em solução tampão acetato de sódio $60 \mathrm{mM}, \mathrm{pH} 4,6$. Em seguida, para cada $2 \mathrm{~mL}$ dessa solução, foi adicionado $25 \mu \mathrm{L}$ de ácido caprílico resfriado. Essa mistura foi lentamente homogeneizada por 30 minutos à temperatura de $25^{\circ} \mathrm{C}$. Posteriormente, foi centrifugada a $3.300 \mathrm{~g}$ por 30 minutos, a $4^{\circ} \mathrm{C}$. Ao sobrenadante foi adicionado PBS 10 vezes concentrado, na proporção de 1:10 (v/v), o $\mathrm{pH}$ foi ajustado para 7,6 com hidróxido de sódio $(\mathrm{NaOH}) 4 \mathrm{M}$ e submetido ao fracionamento, utilizando-se solução saturada de sulfato de amônia (PAGE e THORPE 1998). Após adição do sal, a mistura foi incubada sob agitação constante a $4^{\circ} \mathrm{C}$, por 1 hora, e posteriormente centrifugada a $5.000 \mathrm{~g}$ por 30 minutos, a $4^{\circ} \mathrm{C}$. O sobrenadante foi então descartado e o precipitado ressuspenso em até $1 / 4$ do volume inicial em PBS, $\mathrm{pH} 7,6$, e submetido à diálise por 48 horas, a $4^{\circ} \mathrm{C}$, contra $\mathrm{PBS}$ pH 7,6, sendo essa solução trocada a cada quatro horas (BRACHT \& ISHII-IWAMOTO, 2002). Em seguida, o soro padrão foi titulado, em diluições duplas, frente ao antígeno e usado como 2 UP.

A macro-IDGA foi realizada conforme instruções do fabricante (Biovetech, Recife-PE). A
micro-IDGA foi realizada em placas de Petri (Vetec Química Fina Ltda, Rio de Janeiro - RJ) descartáveis, de $90 \mathrm{~mm}$ de diâmetro. Cada placa continha $16 \mathrm{~mL}$ de Agarose (Sigma-Aldrich Chemie Gmbh, German) 1\% (p/v) em solução tampão borato de sódio (108 mM, pH 8,6). No momento dos testes, o gel foi perfurado com o molde em forma hexagonal (Figura 1), de maneira a formar sete poços, sendo um central, onde foi adicionado o $\mathrm{Ag}$, e seis periféricos equidistantes, onde foram adicionados, de forma alternada, o SP e os soros a serem testados. Os poços destinados ao soro padrão e ao antígeno tinham $3 \mathrm{~mm}$ de diâmetro, com capacidade para $10 \mu \mathrm{L}$ de cada reagente, e os destinados aos soros a serem testados, $5 \mathrm{~mm}(30 \mu \mathrm{L})$, equidistantes $2 \mathrm{~mm}$. Terminada a adição dos reagentes, as placas foram incubadas em câmara úmida à temperatura em torno de $25^{\circ} \mathrm{C}$ e realizadas leitura após $24 \mathrm{~h}$ e $48 \mathrm{~h}$ de incubação. Os soros foram considerados positivos quando ocorria a formação de linha de precipitação entre o poço central $(\mathrm{Ag})$ e o soro testado apresentando identidade com a linha formada entre o SP e o Ag.

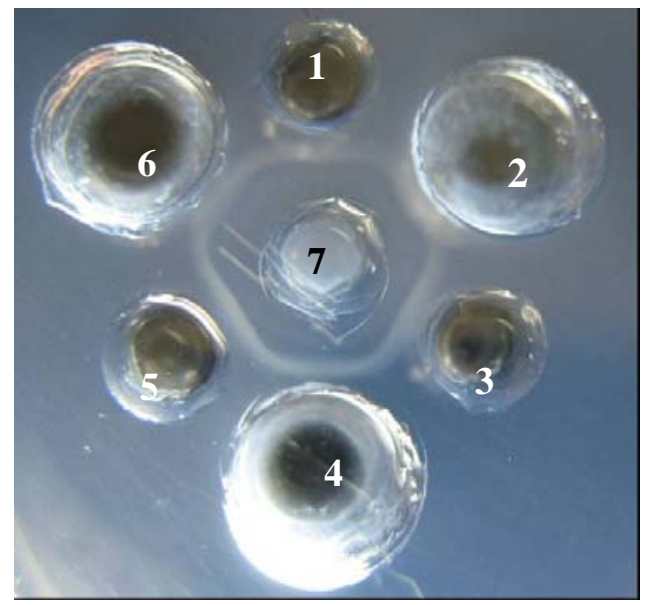

Figura 1 - Fotografia de molde utilizado na microIDGA. Nos poços 1,3 e 5 são distribuídos $10 \mu \mathrm{L}$ de soro padrão; nos poços 2,4 e $6,30 \mu \mathrm{L}$ dos soros a serem testados e no poço $710 \mu \mathrm{L}$ do antígeno

A macro-IDGA é a técnica preconizada pela OIE para o diagnóstico sorológico de LVPR, sendo, neste trabalho, considerada o standard gold $\mathrm{e}$ utilizada como comparativo para a micro-IDGA. A comparação entre a micro e a macro-IDGA foi realizada através do indicador de concordância ajustada Kappa (K), sensibilidade e especificidade relativas (PEREIRA 1999), calculados com base no 
teste de 447 amostras de soros caprinos, colhidos em animais leiteiros de 24 propriedades, localizadas no Rio Grande do Norte (1), Pernambuco (22) e Paraíba (1). Além disso, foram comparadas, qualitativamente, a intensidade e nitidez das linhas de precipitação de ambos os testes, após 24 e 48 horas de incubação das placas.

Para avaliar a estabilidade dos antígenos e soro controle positivo, alíquotas de $100 \mu$ foram descongeladas mensalmente, durante doze meses, e testadas conforme descrito para a micro-IDGA.

\section{RESULTADOS E DISCUSSÃO}

Dos 447 soros caprinos testados, 63 (14,09\%) e $60(13,42 \%)$ apresentaram resultados positivos na micro-IDGA e macro-IDGA, respectivamente (Tabela 1). Quando comparados os resultados, observou-se significativa concordância ajustada Kappa entre os dois testes $(k=0,90)$, com sensibilidade e especificidade da macro-IDGA em relação à micro-IDGA de $93,33 \%$ e $98,20 \%$.

Tabela 1 - Resultado dos testes de 447 soros caprinos submetidos à macro-imunodifusão em gel de agar (Macro-IDGA) e à micro-imunodifusão (Micro-IDGA) para pesquisa de anticorpos contra os Lentivírus de Pequenos Ruminantes (LVPR)

\begin{tabular}{lccc}
\hline & \multicolumn{2}{c}{ Macro-IDGA } & Total \\
\cline { 2 - 4 } Micro-IDGA & Positivo & Negativo & 63 \\
Positivo & 56 & 7 & 384 \\
Negativo & 4 & 380 & 447 \\
\hline Total & 60 & 387 & \\
\hline
\end{tabular}

Sensibilidade $=93,33 \%$

Especificidade $=98,20 \%$

Kappa $=0,90$

Ao avaliar as características qualitativas, como a intensidade da linha de precipitação e nitidez, de acordo com o tempo para determinação de resultados, observou-se que a micro-IDGA apresentou reações mais nítidas do que a macroIDGA, na leitura dos controles positivos feita após 24 horas de incubação; entretanto, não houve diferença de resultado na leitura realizada após 48 horas de incubação. No que diz respeito aos soros testes na micro-IDGA, a leitura conclusiva pôde ser realizada com 24 horas, mesmo em animais fracopositivos, enquanto que na macro-IDGA o tempo foi de 48 horas. GOUVEIA et al. (2000) também afirmaram ter observado maior nitidez no teste realizado com menor volume dos reagentes. Classicamente, o tempo de leitura definitiva das placas de IDGA é realizado entre 48 a 72 horas (ADAMS \& GORHAM, 1986; ABREU et al., 1998).

Em testes de imunodifusão ocorre a migração dupla de antígeno e anticorpos, através do gel de agar. Muitas variáveis podem ser estudadas e modificadas quando se pretende aprimorar esse teste, dentre elas pode-se ressaltar: a concentração dos reagentes, os constituintes do agar e da solução tampão utilizada, o molde para perfuração do gel, desde o seu formato até o tamanho e distância entre poços, bem como seu arranjo no molde. $\mathrm{O}$ encontro dos reagentes em proporções ótimas leva à formação de complexos antígeno-anticorpo insolúveis que precipitam, tornando-se visíveis sob a forma de uma linha ou banda de precipitação. Uma variação extrema na concentração de antígeno e anticorpo pode alterar a localização ou até inibir a formação da mesma, por isso foram feitas as titulações dos Ag e SP, ajustando-os para 2 UP. Essa reação pode ainda ser influenciada por condições físico-químicas, como a concentração eletrolítica, a solução tampão empregada na preparação do gel, o $\mathrm{pH}$ e a temperatura e/ou pela presença de altos níveis de lipídeos nos soros testes. Na realização de ambas as provas de IDGA foi utilizada agarose com alto grau de pureza, que apresenta um baixo ponto de fusão, o que pode ter sido um fator importante para a obtenção de linhas de precipitação mais nítidas, facilitando a leitura das reações. Além disso, é considerado ponto crítico para o teste de IDGA o uso do tampão borato de $\mathrm{pH}$ alcalino (WINWARD et al., 1979).

$\mathrm{Na}$ micro-IDGA utilizou-se um molde em forma hexagonal com os poços destinados aos $\mathrm{Ag} \mathrm{e}$ SP de capacidade para $10 \mu \mathrm{L}$ e os para os soros a serem testados com capacidade para $30 \mu \mathrm{L}$. O uso de maior volume do soro pode permitir a detecção de animais que apresentam baixos títulos de anticorpos.

Muitos modelos de molde já foram propostos, porém o que predomina é o de formato hexagonal 
com poços de igual diâmetro e equidistantes, sendo um poço central, onde se distribui o antígeno, e seis periféricos, onde se distribui alternadamente os soros de referência e os soros a serem testados (CUTLIP et al., 1977; WINWARD et al., 1979; ADAMS \& GORHAM, 1986; ABREU et al., 1998; GOUVEIA, 1994). O molde usado na micro-IDGA apresenta vantagens, pois se torna possível testar mais animais por placa, pois na macro-IDGA são testados 21 soros em sete conjuntos, enquanto na micro-IDGA são testados 30 soros, e pode-se empregar maior quantidade do soro teste em relação ao antígeno. Além disso, há menor consumo de antígeno e soro padrão, insumos responsáveis, em grande parte, pelo custo do teste, pois metade desses reagentes é utilizada.

A validade de um teste diagnóstico pode ser estimada com base em seus valores intrínsecos (sensibilidade e especificidade), que são próprios do teste e não sofrem influência da prevalência da enfermidade para a qual se destina seu uso (ASTUDILLO \& KANTOR, 1981). Classicamente, a sensibilidade é definida como o percentual de verdadeiros positivos identificados no teste, e a especificidade como o dos verdadeiros negativos, quando comparados com um teste de referência, que pode ser um teste consagrado como standard gold ou outro de uso clássico. Pelas particularidades da patogênese dos LVPR, a determinação do verdadeiro status dos animais é difícil, pois a restrição da replicação viral torna $\mathrm{o}$ isolamento incerto (HECKERT et al., 1992; RIMSTAD et al., 1993; CHEBLOUNE et al., 1996) e não se dispõe de um teste sorológico standard gold (de ANDRÉS et al., 2005). Por isso, foi adotado o critério de cálculo da sensibilidade e da especificidade com base nos resultados de uma macro-IDGA, que é rotineiramente usada no país e preconizada pela OIE para diagnóstico de LVPR, que apresenta sensibilidade de $79,7 \%$ e especificidade de $100 \%$, (relativas a um ELISA-i). Assim, considerando a significativa concordância entre a micro e a macroIDGA, esses valores podem, genericamente, ser aplicados à micro-IDGA.

Nos testes de IDGA para LVPR, a sensibilidade e especificidade são dependentes do tipo de antígeno empregado. Os antígenos utilizados neste trabalho foram produzidos em células de MS infectadas com CAEV-Co, constituído principalmente de nucleoproteína viral, pois se tem observado que os testes com antígeno CAEV são mais sensíveis do que aqueles com MV (KNOWLES et al., 1994; ABREU et al., 1998). Por outro lado, ADAMS \& GORHAM (1986) afirmam que o teste utilizando a glicoproteína de superfície (gp135) do vírus CAEV é mais sensível do que os que empregam a nucleoproteína (p28), porém KNOWLES et al. (1994) observaram sensibilidade e especificidade de $91 \%$ e $100 \%$, respectivamente, quando utilizaram como antígeno o vírus inteiro CAEV-63. A relativa instabilidade das glicoproteínas virais (RIMSTAD et al., 1994) justifica a utilização da nucleoproteína na constituição de kits, que têm se mostrado bastante estáveis. Neste trabalho, isso ficou evidente na prova de estabilidade de longa duração, na qual, após um ano não, houve redução do título do antígeno.

Finalmente, em consonância com a preocupação com a bioética e a biossegurança, a tecnologia usada na micro-IDGA reduzirá a quantidade de soro controle positivo que é colhido de caprino naturalmente infectado por CAEV. Isso implica o uso de menor número de animais, o que está de acordo com os preceitos de bem estar animal, e na manipulação menos frequente de células e animais infectados pelo vírus, que, apesar de não ser considerado infectante para o homem, deve ser objeto de atenção, pois é um vírus altamente mutável. Além disso, como regra geral de prevenção à exposição a agentes infecciosos, é importante destacar que agentes desconhecidos podem infectar os animais sem serem detectados, impondo algum tipo de risco aos que os manipulam, devendo-se, assim, limitar ao máximo o uso de animais.

\section{CONCLUSÕES}

A micro-IDGA pode substituir a macro-IDGA no diagnóstico sorológico de LVPR, diminuindo os custos do teste. Na micro-IDGA o tempo de leitura dos resultados pode ser reduzido para 24 horas, sem comprometimento da confiabilidade dos resultados, mesmo nos casos de animais com reações fracopositivas.

\section{AGRADECIMENTOS}

À Fundação de Amparo à Ciência e Tecnologia do Estado de Pernambuco (FACEPE) e à Financiadora de Estudos e Projetos (FINEP) pelo apoio financeiro.

\section{REFERENCIAS}

ABREU S.R.O., CASTRO R.S., NASCIMENTO S.A.; SOUZA M.G. Produção de antígeno nucleoproteíco do vírus da Artrite-Encefalite Caprina e comparação com o do vírus Maedi- Visna para utilização em teste de imunodifusão em agar gel. Pesquisa Veterinária Brasileira, v.18, n.2,: p. 57-60. 1998.

ADAMS D. S.; GORHAM J. R. The gp135 of caprine 
arthritis-encephalitis virus affords greater sensitivity than the p28 in immunidufision serology. Research in Veterinary Science, v.40, p.157-160, 1986.

ASTUDILLO V.M.; KANTOR I.N.. El problema de la validez de una prueba diagnostica para uso masivo como procedimento estadistico de clasificación. Boletin del Centro Panamericano de Fiebre Aftosa, n.43-44, p.3743, 1981.

BLACKLAWS B.A., BERRIATUA E., TORSTEINSDOTTIR S., WATT N.J., ANDRÉS D., KLEIN D.; HARKISS G.D.. Transmission of small ruminant lentiviruses Veterinary Microbiology, v. 101, n.3, p. 199-208, 2004.

BRACHT A.; ISHII-IWAMOTO E. L.. Métodos de laboratório em bioquímica. $1^{\mathrm{a}}$ Ed. Manole, São Paulo, 2002. p. 77-192.

BRASIL. MINISTÉRIO DA AGRICULTURA PECUÁRIA E ABASTECIMENTO. Instrução Normativa $\mathbf{N}^{\mathbf{0}}$ 87, DE 10 DE DEZEMBRO DE 2004a. Disponível em: <http:www.agricultura.gov.br>, acessado em 04/04/2006.

BRASIL. MINISTÉRIO DA AGRICULTURA PECUÁRIA E ABASTECIMENTO. Portaria $\mathbf{N}^{\mathbf{0}} \mathbf{1 0 3}$, DE 07 DE DEZEMBRO DE 2004b. Disponível em: $<$ http:www.agricultura.gov.br>, acessado em 04/04/2006.

CALLADO A.K.C., CASTRO R.S. e TEIXEIRA, M.F.S. Lentivírus de Pequenos Ruminantes (CAEV e MaediVisna): Revisão e perspectivas. Pesquisa Veterinária Brasileira, v. 21, p. 87-97, 2001.

CHEBLOUNE Y., SHEFFER D.R., KAR B.M., STEPHENS E.; NARAYAN O. Restrictive type of replication of ovine/caprine lentiviruses in ovine fibroblast cell culture. Virology, v. 222, p. 21-30, 1996.

CRUZ, J.C.M. Monitoramento sorológico e da presença do DNA pró-viral do lentivírus caprino (CAEV) no sangue e sêmen de reprodutores infectados. 2009. $35 \mathrm{f}$. Tese (Doutorado em Ciência Animal), Universidade Federal de Minas Gerais, Minas Gerais. Disponível em: http://www.bibliotecadigital.ufmg.br/dspace/bitstream/184 3/SSLA-

83KNSV/1/tese_juliano_cezar_minardi_da_cruz.pdf

CUTLIP R.C., JACKSON T.A.; LAIRD, G.A. Immunodifusion test for ovine progressive pneumonia. American Journal of Veterinarian Research, v.38, p. 1081-1084, 1977.

de ANDRÉS D., KLEIN D., WATT N.J., BERRIATUA E., TORSTCINSDOTTIR S., BLACKLAWS, B.A.; HARKISS, G.D. Diagnostic tests for small ruminant lentiviruses. Veterinary Microbiology, v.107, p. 49-62, 2005.

GOUVEIA, A.M. Padronização de microtécnica de imunodifusão em gel de agarose para diagnóstico de lentivírus da pneumonia progressiva ovina (OPP), maedivisna (MVV) e artrite encefalite caprina (CAEV). Sobral, 1994. 4p. (Mimeografado).

HECKERT R.A., MCNAB W.B., RICHARDSON S.M.; BISCOE, M.R. Evaluation of an enzime-linked immunosorbent assay for the detection of antibodies to caprine arthritis-encephalitis virus in goat serum. Canadian Journal of Veterinary Research, v. 56, n.2, p. 237-241, 1992.

KNOWLES D.P., EVERMANN J.F., SHROPSHINRE C., VANDER SCHALIE J., BRADWAY D., GEZON H.M.; CHEEVERS W.P. Evaluation of agar gel immunodiffusion serology using caprine and ovine lentiviral antigens for detection of antibody to caprine arthritis-encephalitis virus. Journal of Clinical Microbiology, v. 32, n. 1, p.243-245, 1994.

OIE. Organização Mundial de Saúde Animal, 2010. Disponível em <http://www.oie.int $>$, Acesso em $10 \mathrm{de}$ dezembro de 2010.

PAGE M. e THORPE R. Methods in Molecular Biology: Immunochemical protocols. 2ed. Ed. Manole, São Paulo, p. 95-111, 1998.

PEREIRA M.G. Epidemiologia: teoria e prática. Guanabara Koogan, Rio de Janeiro, 1999. p. 358-376.

RIMSTAD E., EAST N., DEROCK E., HIGGINS J. ;PEDERSEN N.C. Detection of antibodies to caprine arthritis-encephalitis virus using recombinant gag proteins. Archives of Virology, v. 134, p. 345-356, 1994.

RIMSTAD E., EAST N.E., TORTEN M., HIGGINS J., DEROCK E.; PEDERSEN N.C. Delayed seroconversion following naturally acquired caprine arthritis-encephalitis virus infection in goats. American Journal of Veterinarian Research, v. 54, p. 1858-1862, 1993.

SHAH, C.; HUDER, J. B.; BÖNI, J., SCHÖNMANN M., MÜHLHERR J., LUTZ H.; SCHÜPBACH J. Phylogenetic analysis and reclassification of caprine and ovine lentiviruses based on 104 new isolates: evidence for regular sheep-to-goat transmission and world propagation through livestock trade. Virology, v. 319, p. 12-26, 2004.

WINWARD L.D., LEENDERTSEN L. e SHEN D.T. Microimmunodiffusion Test for Diagnosis of Ovine Progressive Pneumonia. American Journal of Veterinarian Research, v. 40, p. 564-566, 1979. 